\title{
Sex differences in the association between major risk factors and the risk of stroke in the UK Biobank cohort study
}

Sanne A.E. Peters, PhD, Cheryl Carcel, MD, PhD, Elizabeth R.C. Millett, PhD, and Mark Woodward, PhD

Neurology ${ }^{\circledR}$ 2020;95:e2715-e2726. doi:10.1212/WNL.0000000000010982

\begin{abstract}
Objective

To determine whether there are sex differences in the association between risk factors and incident stroke, including stroke subtypes.
\end{abstract}

\section{Methods}

A total of 471,971 (56\% women) UK Biobank participants without a history of cardiovascular disease were included. During 9 years of follow-up, 4,662 (44\% women) cases of stroke were recorded. Cox models yielded adjusted hazard ratios (HRs) and women-to-men ratios of HRs (RHRs) for stroke associated with 7 risk factors.

\section{Results}

The incidence rate per 10,000 person-years was $8.66(8.29-9.04)$ in women and 13.96 (13.44-14.50) in men for any stroke, $6.06(5.75-6.38)$ in women and $11.35(10.88$; 11.84) in men for ischemic stroke, and $1.56(1.41-1.73)$ in women and 2.23 (2.02-2.45) in men for hemorrhagic stroke. The association between increases in blood pressure, body anthropometry, and lipids, diabetes, and atrial fibrillation and any stroke was similar between men and women. Hypertension, smoking, and a low socioeconomic status were associated with a greater HR of any stroke in women than men; the RHRs were 1.36 (1.26-1.47), 1.18 (1.02-1.36), and 1.17 (1.03-1.33), respectively. Diabetes was associated with a higher HR of ischemic stroke in women than men (RHR 1.25 [1.00-1.56]). Atrial fibrillation was associated with a higher HR of hemorrhagic stroke in women than men (RHR $2.80[1.07-7.36])$.

\section{Conclusion}

Several risk factors are more strongly associated with the risk of any stroke or stroke subtypes in women compared with men. Despite this, the incidence of stroke remains higher among men than women.

\author{
Correspondence \\ Dr. Peters \\ speters@ \\ georgeinstitute.org.uk
}

\section{RELATED ARTICLE}

\section{Editorial}

Sex differences in modifiable stroke risk factors: The next step in personalized stroke prevention

Page 891 


\section{Glossary}

BiomarCaRE $=$ Biomarker for Cardiovascular Risk Assessment in Europe; BMI $=$ body mass index; $\mathbf{C I}=$ confidence interval; DBP = diastolic blood pressure; HR = hazard ratio; ICD-10 = International Classification of Diseases, 10th revision; $\mathbf{M I}=$ myocardial infarction; REGARDS = Reasons for Geographic and Racial Differences in Stroke; SBP = systolic blood pressure.

\section{Women Vs Men: Differences in Links Between Major Risk Factors and Risk of Stroke}

Associations between various risk factors and the risk of stroke differ between women and men

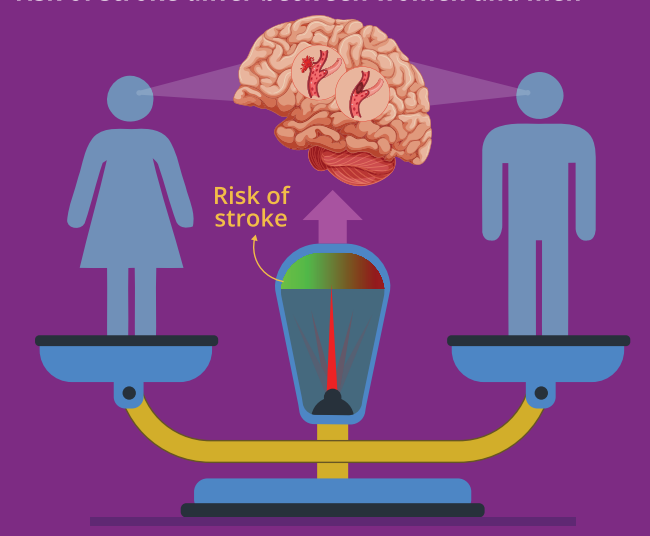

However, detailed and comprehensive assessment of these differences is lacking

Study question

How do the associations between major risk factors and stroke risk vary by sex for various types of stroke?

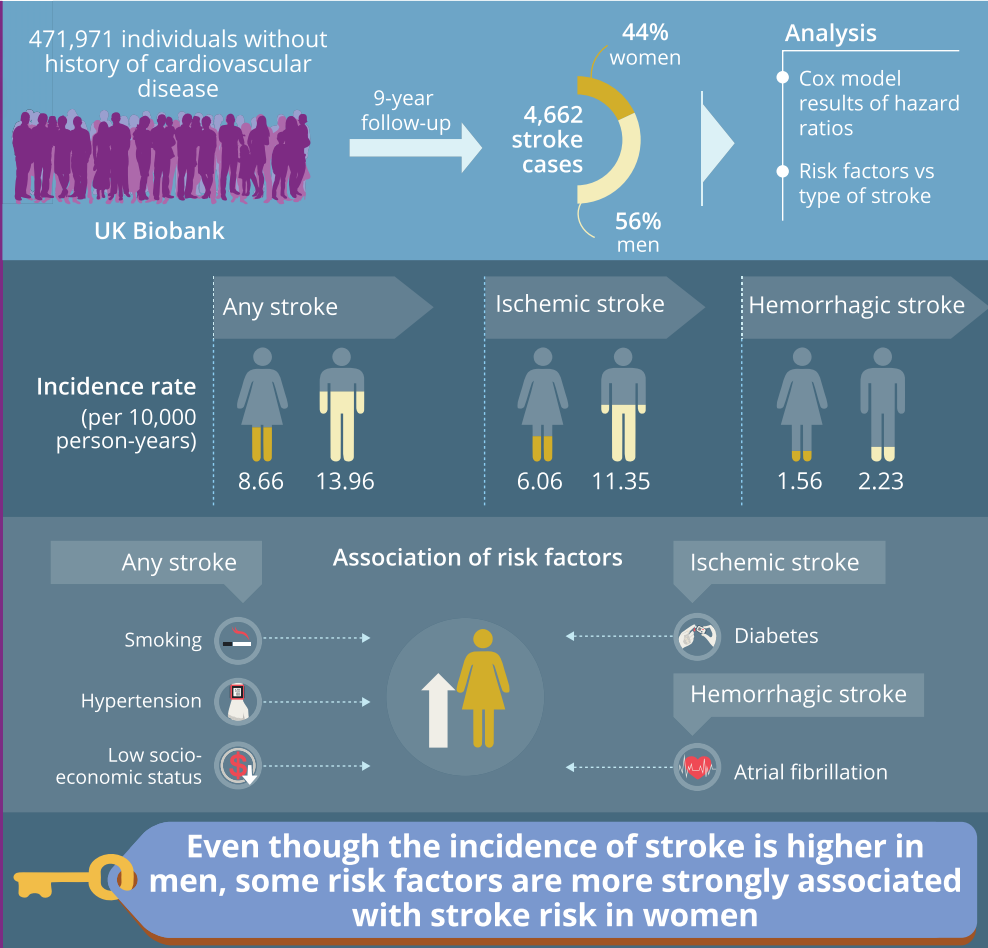

Neurology"

doi:10.1212/WNL.0000000000010982

Copyright $\odot 2020$ American Academy of Neurology

Stroke is the second leading cause of death and disability worldwide, accounting for $11 \%$ of deaths in women and $10 \%$ of deaths in men in 2017. ${ }^{1}$ The INTERSTROKE study showed that $\approx 90 \%$ of the burden of stroke could be attributed to 10 potentially modifiable risk factors, with hypertension alone contributing to $\approx 50 \%$ of the burden. ${ }^{1,2}$

There are considerable differences between women and men in the clinical presentation, medical care, and prognosis and outcomes of stroke, which can be explained in part by women's longer life expectancy. ${ }^{3,4}$ Moreover, INTERSTROKE demonstrated that cardiac disease and waist-to-hip ratio, a measure of body fat distribution, were more strongly associated with the risk of stroke in women than men. ${ }^{2}$ While INTERSTROKE had a case-control design, findings from large-scale meta-analyses of prospective studies have provided additional evidence for clinically meaningful sex differences in the effects of some, but not all, major risk factors on the risk of stroke, mostly to the detriment of women. ${ }^{5-10}$ For example, the presence of diabetes was associated with a $27 \%$ greater excess risk of stroke in women than in men. ${ }^{7}$ Similarly, a history of atrial fibrillation was associated with a $99 \%$ higher excess risk of stroke. ${ }^{6}$ However, meta-analyses of published studies have a substantial amount of heterogeneity in study design, analyses, and populations and cannot be used to assess whether any potential sex differences are most prominent in certain subpopulations such as among younger individuals or those from disadvantaged socioeconomic backgrounds. Moreover, meta-analyses generally were focused on a single risk factor and did not assess the sex-specific comparative effect of risk factor components on the risk of stroke. In addition, these metaanalyses could not make comparisons of sex differences in the effects of risk factors on the absolute risk of stroke, thus limiting the implications for clinical decision-making. Finally, previous studies on sex differences in risk factors for stroke typically focused on all stroke only, without separate analyses of biologically distinct stroke subtypes.

The aim of this study was therefore to conduct a detailed assessment of the sex-specific association of major risk factors and the risk of incident ischemic and hemorrhagic, as well as total, stroke among 470,000 women and men in the UK Biobank.

\section{Methods}

\section{Standard protocol approvals, registrations, and patient consents}

The UK Biobank has obtained Research Tissue Bank approval from its governing Research Ethics Committee, as recommended 
by the National Research Ethics Service. No separate ethics approval was required.

\section{Study population}

The UK Biobank is a large, prospective, population-based cohort study. ${ }^{11,12}$ Between 2006 and 2010, > 500,000 women and men (5.5\% response rate) 40 to 69 years of age at baseline attended 1 of the 22 centers across the United Kingdom. UK Biobank participants are not representative of the general population, being healthier and less likely to be relatively more socially deprived. The present analyses were restricted to participants without a self-reported history of cardiovascular disease at baseline.

\section{Measurement of risk factors}

At study baseline, participants provided informed consent electronically, completed questionnaires on their lifestyle and medical history, and had physical and functional measurements performed. Seated systolic blood pressure (SBP) and diastolic blood pressure (DBP) were measured twice with the OMRON HEM-7015IT digital blood pressure monitor (Kyoto, Japan). Pulse pressure was calculated as SBP minus DBP. Mean arterial pressure was defined as DBP plus pulse pressure divided by 3 . Hypertension was categorized into 4 groups according to the 2017 American College of Cardiology/American Heart Association guidelines; normal (SBP $<120 \mathrm{~mm} \mathrm{Hg}$ and DBP $<80 \mathrm{~mm} \mathrm{Hg}$ ), elevated (SBP 120-129 mm Hg and DBP $<80 \mathrm{~mm} \mathrm{Hg}$ ), stage 1 hypertension (SBP 130-139 mm Hg or DBP $80-89 \mathrm{~mm} \mathrm{Hg}$ ), and stage 2 hypertension ( $\mathrm{SBP} \geq 140 \mathrm{~mm}$ $\mathrm{Hg}$ or $\mathrm{DBP} \geq 90 \mathrm{~mm} \mathrm{Hg}) .{ }^{13}$ Smoking status and the number of cigarettes smoked per day were self-reported, as were a medical history of diabetes mellitus, age at first diagnosis of diabetes, the use of medications for diabetes regulation, and a medical history of atrial fibrillation. Type 1 diabetes was defined as the combination of a history of diabetes, age at first diagnosis before 30 years, and the use of an insulin product. All other participants with a self-reported medical history of diabetes were considered to have type 2 diabetes. Body weight was measured with the Tanita BC-418 MA body composition analyzer (Tokyo, Japan). Waist and hip circumference were measured with a Wessex nonstretchable sprung tape measure (Andover, UK). Standing height was measured with a Seca 202 measure (Hamburg, Germany). Body mass index (BMI) was calculated by dividing weight (kilograms) over height (meters) squared. Overweight and obesity were defined as a BMI $\geq 25$ to $<30 \mathrm{~kg} / \mathrm{m}^{2}$ and $\geq 30 \mathrm{~kg} / \mathrm{m}^{2}$, respectively. Waist-to-hip ratio was the waist circumference divided by hip circumference, and waist-to-height ratio was the waist circumference divided by standing height. Blood lipid levels were determined with the Beckman Coulter AU5800 (Sharon Hill, PA). Elevated total cholesterol was defined as a total cholesterol level $\geq 6.2 \mathrm{mmol} /$ L. Socioeconomic status was determined with the Townsend deprivation index, a measure of area deprivation.

\section{Study outcomes}

The primary study endpoints were the incidence of fatal or nonfatal ischemic stroke (I63 or I64), hemorrhagic stroke
(I61), and all stroke as defined by codes I60, I61, I63, or I64 in ICD-10. Outcome adjudication for incident stroke was conducted by the UK Biobank Outcome Adjudication Group and involved linkage with hospital admissions data from England, Scotland, and Wales and the national death register to identify the date of the first known stroke after the date of baseline assessment. Follow-up started at inclusion in the UK Biobank and ended on February 1, 2018, date of death, or the first nonfatal stroke, for all participants.

\section{Statistical analyses}

Baseline characteristics are presented as means (SDs) for continuous variables and as percentages for categorical variables. Cox regression models were used to obtain hazard ratios (HRs) and 95\% confidence intervals (CIs) of stroke and stroke subtypes associated with each risk factor separately for women and men. An interaction term was added to the model to obtain the women-to-men ratio of HRs and 95\% CIs, which were used to evaluate whether the HRs differed between the sexes. For comparisons involving $>2$ groups, CIs were estimated from floating absolute risks, enabling valid comparisons between any 2 groups, even if neither is the baseline group.

All models were adjusted for age, with different sets of additional covariables, selected a priori, across risk factors in the multivariable analyses. For blood pressure-related variables, models were also adjusted for smoking status, use of lipid levelregulating medication, use of antihypertensive medication, total cholesterol, BMI, diabetes, and socioeconomic status. Smokingrelated variables were in addition adjusted for socioeconomic status. Diabetes-related variables were also adjusted for SBP, use of antihypertensive medications, use of lipid level-regulating medication, smoking status, total cholesterol, BMI, and socioeconomic status. Measures of body anthropometry were in addition adjusted for smoking status and socioeconomic status. Lipid-related variables were adjusted for SBP, use of lipid-level regulating medication, use of antihypertensive medication, smoking status, BMI, and diabetes. Atrial fibrillation was in addition adjusted for SBP, use of antihypertensive medications, use of lipid level-regulating medication, smoking status, total cholesterol, BMI, diabetes, and socioeconomic status. Socioeconomic status was also adjusted for SBP, use of lipid-level regulating medication, use of antihypertensive medication, smoking status, total cholesterol, BMI, and diabetes.

For comparability across measures and between sexes, results are expressed as the HR per sexes-combined 1-SD increase in blood pressure, body anthropometry, or lipid levels. The SDs are $18.6 \mathrm{~mm} \mathrm{Hg}$ for SBP, $10.1 \mathrm{~mm} \mathrm{Hg}$ for DBP, $12.0 \mathrm{~mm} \mathrm{Hg}$ for mean arterial pressure, $13.6 \mathrm{~mm} \mathrm{Hg}$ for pulse pressure, 4.8 for BMI, 13.3 for waist circumference, 0.09 for waist-to-hip ratio, 0.09 for waist-to-height ratio, 1.12 for total cholesterol, 0.38 for high-density lipoprotein cholesterol, and 0.85 for lowdensity lipoprotein cholesterol.

Subgroup analyses were conducted by age group ( $<60$ years vs $\geq 60$ years) and socioeconomic status (Townsend 
Table 1 Baseline characteristics of the study participants

\begin{tabular}{lll}
\hline & Women & Men \\
\hline No. (\%) & $263,295(55.8)$ & $208,676(44.2)$ \\
\hline $\begin{array}{l}\text { Incident stroke during } \\
\text { follow-up, } \mathbf{n}(\%)\end{array}$ & & \\
\hline Any stroke & $2,050(44.0)$ & $2,612(56.0)$ \\
\hline Ischemic stroke & $1,436(40.3)$ & $2,127(59.7)$ \\
\hline Hemorrhagic stroke & $371(47.0)$ & $419(53.0)$ \\
\hline Age, y & $56.2(8.0)$ & $56.3(8.2)$ \\
\hline Blood pressure, mm Hg & & \\
\hline Systolic BP & $135.2(19.2)$ & $141.1(17.4)$ \\
\hline Diastolic BP & $80.8(10.0)$ & $84.5(9.9)$ \\
\hline Pulse pressure & $54.4(14.2)$ & $56.6(12.6)$ \\
\hline Mean arterial pressure & $98.9(12.0)$ & $103.3(11.4)$ \\
\hline Hypertension, \% & & 15.6 \\
\hline Elevated BP & 13.0 & 11.1 \\
\hline Stage 1 hypertension & 26.4 & 27.6 \\
\hline Stage 2 hypertension & 39.9 & 52.7 \\
\hline $\begin{array}{l}\text { Use of antihypertensive } \\
\text { medication, \% }\end{array}$ & 12.3 & 15.6 \\
\hline Smoking status, & & \\
\hline
\end{tabular}

Smoking status, \%

\begin{tabular}{lll}
\hline Ex & 31.0 & 36.9 \\
\hline Current & 8.8 & 12.4
\end{tabular}

Smoking intensity,

cigarettes per day, \%a

\begin{tabular}{lll}
\hline $\mathbf{1 - 9}$ & $24.4(5.4[1.9])$ & $16.3(5.5[2.0])$ \\
\hline $\mathbf{1 0 - 1 9}$ & $45.7(12.8$ & $39.7(13.0$ \\
& $[2.5])$ & $[2.5])$ \\
\hline $\mathbf{2 0}$ & $29.9(22.7$ & $44.1(24.7$ \\
& $[5.4])$ & $[7.4])$ \\
\hline
\end{tabular}

Diabetes, \%

\begin{tabular}{lll}
\hline Type $\mathbf{1}$ & 0.2 & 0.3 \\
\hline Type $\mathbf{2}$ & 3.3 & 5.7 \\
\hline $\begin{array}{l}\text { Use of glucose-lowering } \\
\text { drugs, } \mathbf{\%}^{\mathbf{b}}\end{array}$ & 59.5 & 64.9 \\
\hline
\end{tabular}

Body anthropometry

\begin{tabular}{lll}
\hline BMI, kg/m & $27.0(5.2)$ & $27.7(4.2)$ \\
\hline Waist circumference, cm & $84.5(12.4)$ & $96.6(11.2)$ \\
\hline Waist-to-hip ratio & $0.8(0.1)$ & $0.9(0.1)$ \\
\hline Waist-to-height ratio & $0.5(0.1)$ & $0.5(0.1)$ \\
\hline BMI categories, \% & & \\
\hline Overweight & 36.5 & 49.3 \\
\hline Obese & 22.9 & 24.1 \\
\hline
\end{tabular}

Table 1 Baseline characteristics of the study participants (continued)

\begin{tabular}{|c|c|c|}
\hline & Women & Men \\
\hline \multicolumn{3}{|l|}{ Lipids, mmol/L } \\
\hline $\begin{array}{l}\text { Total cholesterol, \% } \\
\text { elevated }\end{array}$ & $5.9(3.7), 34.8$ & $5.6(1.1), 25.6$ \\
\hline $\begin{array}{l}\text { Low-density lipoprotein } \\
\text { cholesterol }\end{array}$ & $3.7(0.9)$ & $3.6(0.8)$ \\
\hline $\begin{array}{l}\text { High-density lipoprotein } \\
\text { cholesterol }\end{array}$ & $1.6(0.4)$ & $1.3(0.3)$ \\
\hline $\begin{array}{l}\text { Use of lipid-lowering } \\
\text { drugs, \% }\end{array}$ & 8.8 & 14.2 \\
\hline Atrial fibrillation, $\%$ & 0.4 & 1.0 \\
\hline Use of warfarin, \%c & 90.2 & 94.6 \\
\hline \multicolumn{3}{|l|}{ Socioeconomic status, \% } \\
\hline Middle third & 30.0 & 29.1 \\
\hline Upper third & 51.1 & 51.1 \\
\hline
\end{tabular}

Abbreviations: $\mathrm{BMI}=$ body mass index; $\mathrm{BP}=$ blood pressure.

Values are mean (SD) for continuous variables and percentages for categorical variables.

Values are percentage and, in parentheses, the group-specific mean [SD] number of cigarettes per day.

${ }^{\mathrm{b}}$ Among those with type 2 diabetes.

cAmong those with a history of atrial fibrillation.

deprivation index $>-0.56$ [lower] vs Townsend deprivation index $\leq-0.56$ [higher]). For hypertension, diabetes type 2, and lipid-related variables, we stratified the analyses by the use of antihypertensive, glucose level-lowering, and lipid levelregulating medication. For atrial fibrillation, the results were stratified by the self-reported use of warfarin.

We also assessed sex differences in stroke risk associated with risk factors on the absolute scale, which are less likely to be generalizable to other populations than relative risks but can inform clinical decisions. We used Poisson regression to obtain unadjusted and adjusted rates of stroke and stroke subtypes per 10,000 person-years by sex and their women-to-men difference of differences. ${ }^{14}$ Adjustments were the same as those used in the Cox models. Analyses were performed with Stata version 12.0 (StataCorp, College Station, TX) and R version 3.3.0 (R Foundation for Statistical Computing, Vienna, Austria).

\section{Data availability}

Researchers can apply to use the UK Biobank resource and access the data used. No additional data are available.

\section{Results}

Overall, 471,971 (56\% women) individuals were included (table 1). The mean age at study baseline was 56 years. On average, blood pressure levels were higher in men than women, and men were more likely to have ever smoked. The prevalence 
Figure 1 Adjusted HRs for incident ischemic stroke associated with risk factors, by sex

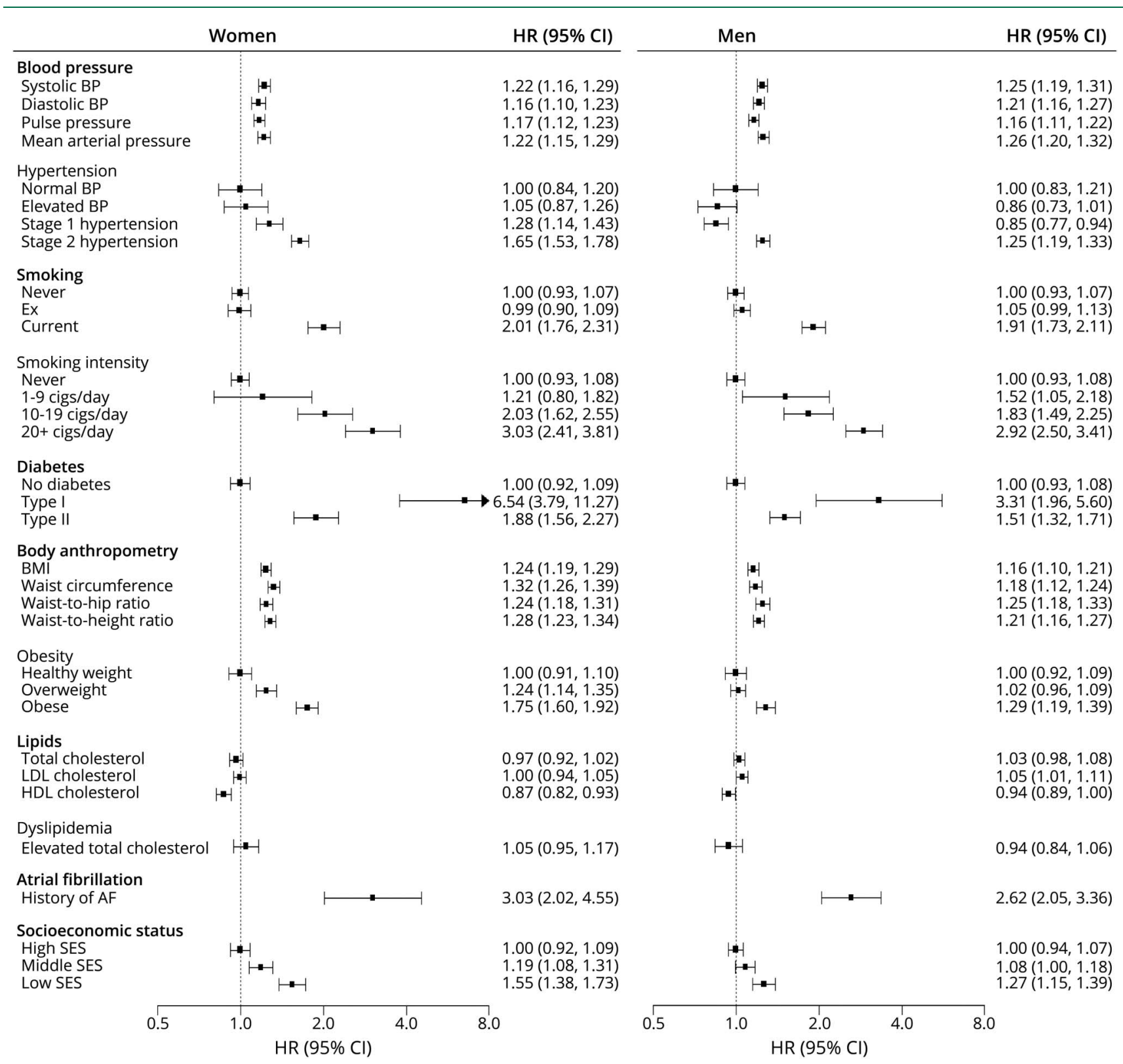

Horizontal lines indicate the corresponding 95\% confidence intervals (Cls) around the hazard ratios (HRs). AF = atrial fibrillation; $\mathrm{BMI}=$ body mass index; $\mathrm{BP}=$ blood pressure; HDL = high-density lipoprotein; LDL = low-density lipoprotein; SES = socioeconomic status.

of diabetes was $6 \%$ in men and $3 \%$ in women. Seventy-four percent of men and 59\% of women were overweight or obese at study baseline. During a median follow-up of 9.0 years, 4,662 (44\% women) incident cases of stroke were documented, including 3,563 (40\% women) cases of ischemic stroke and 790 ( $47 \%$ women) cases of hemorrhagic stroke.

\section{Blood pressure}

The relationship between SBP, DBP, pulse pressure, and mean arterial pressure and the risk of any stroke and stroke subtypes was similar between women and men (figures 1-3 and efigures 1-2, data available online at ora.ox.ac.uk/objects/uuid: 0866f6db-951d-4b3c-9bf9-40615161fa32). Hypertension was more strongly associated with the risk of any stroke and stroke subtypes in women than men; the multiple-adjusted womento-men ratios of HRs associated with stage 2 hypertension were 1.36 (1.26-1.47) for any stroke, 1.32 (1.20-1.44) for ischemic heart disease, and 1.27 (1.05-1.53) for hemorrhagic stroke.

\section{Smoking}

Compared to never smokers, current smokers had a considerably higher risk of any stroke and stroke subtypes, with evidence to suggest that the excess risk of any stroke, but not of stroke subtypes, was greater for women than men. The multiple-adjusted women-to-men ratio of HRs for any stroke associated with current smoking was 1.18 (1.02-1.36) (efigure 2, data available online at ora.ox.ac.uk/objects/uuid:0866f6db951d-4b3c-9bf9-40615161fa32). Although the excess risk of 
Figure 2 Adjusted HRs for incident hemorrhagic stroke associated with risk factors, by sex

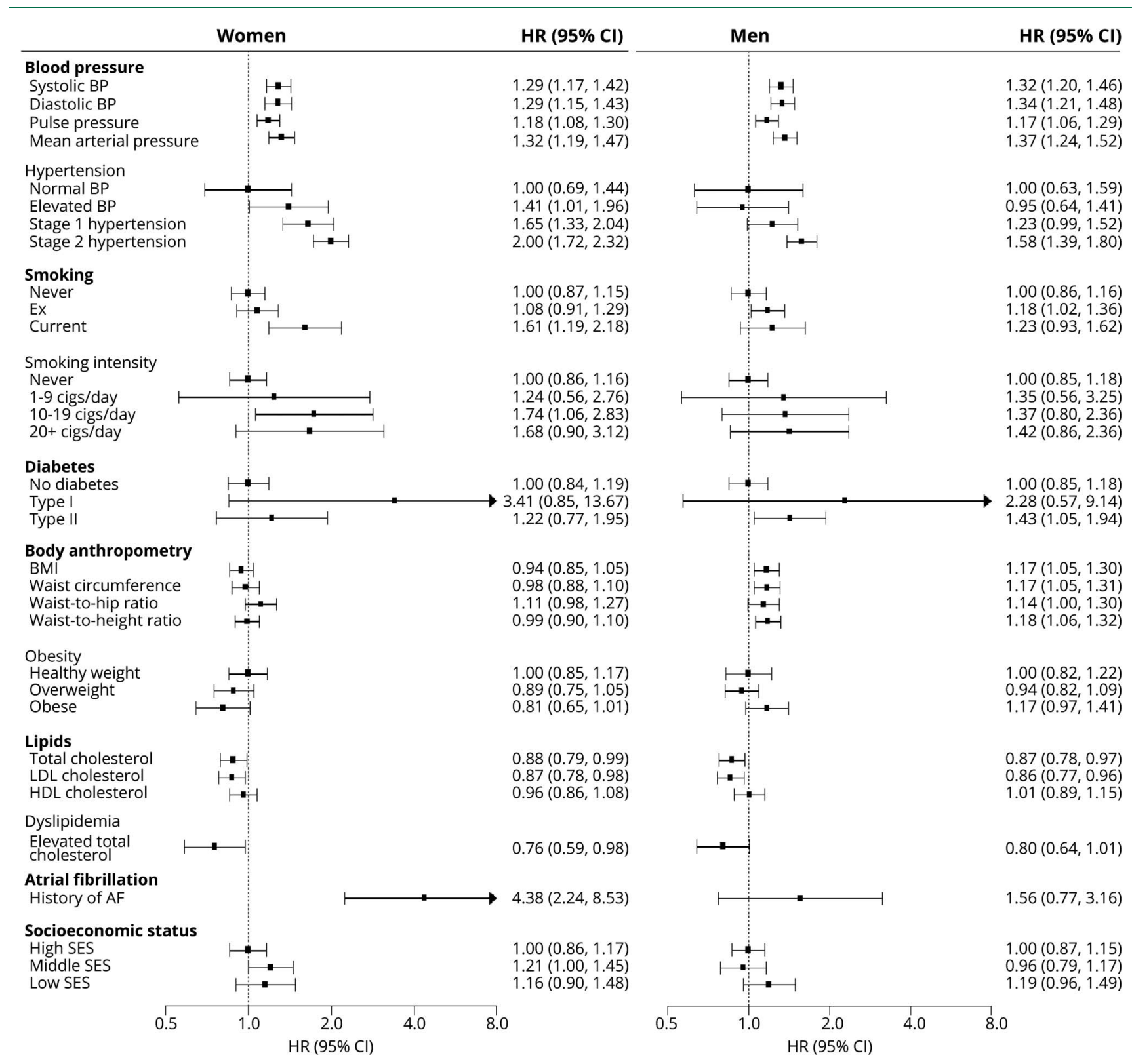

Horizontal lines indicate the corresponding 95\% confidence intervals ( $\mathrm{Cls}$ ) around the hazard ratios (HRs). $\mathrm{AF}=$ atrial fibrillation; $\mathrm{BMI}=\mathrm{body}$ mass index; $\mathrm{BP}=$ blood pressure; HDL = high-density lipoprotein; LDL = low-density lipoprotein; SES = socioeconomic status.

stroke and stroke subtypes associated with current smoking increased with an increasing number of cigarettes per day in both sexes, there was no evidence of a sex difference in the HRs at a given smoking intensity (figure 3 and efigure 2).

\section{Diabetes}

The presence of type 1 diabetes was associated with a substantially higher risk of stroke, especially of ischemic stroke, in both women and men. The multiple-adjusted HR of ischemic stroke associated with type 1 diabetes was 6.54 (3.79-11.27) in women and 3.31 (1.96-5.60) in men (figure 1). The corresponding women-to-men ratio of HRs was 1.97 (0.93-4.20) (figure 3). Type 2 diabetes was associated with an increased the risk of any ischemic in both sexes; the multiple-adjusted
HR was $1.88(1.56-2.27)$ in women and $1.51(1.32-1.71)$ in men (figure 1). The women-to-men ratio of HRs was 1.25 (1.00-1.56) (figure 3).

\section{Body anthropometry}

Each of the body anthropometry indexes was associated with the risk of all stroke and ischemic in both sexes but only with hemorrhagic stroke in men. Obesity was associated with an increased risk of any stroke of $\approx 30 \%$ in both sexes (efigure 1 , data available online at ora.ox.ac.uk/objects/uuid:0866f6db951d-4b3c-9bf9-40615161fa32). For ischemic stroke, the multiple-adjusted HRs associated with obesity were 1.75 $(1.60-1.92)$ in women and $1.29(1.19-1.39)$ in men (figure 1). The corresponding ratio of HRs was 1.36 (1.21-1.54) (figure 3 ). 
Figure 3 Adjusted women-to-men RHRs for ischemic and hemorrhagic stroke associated with risk factors

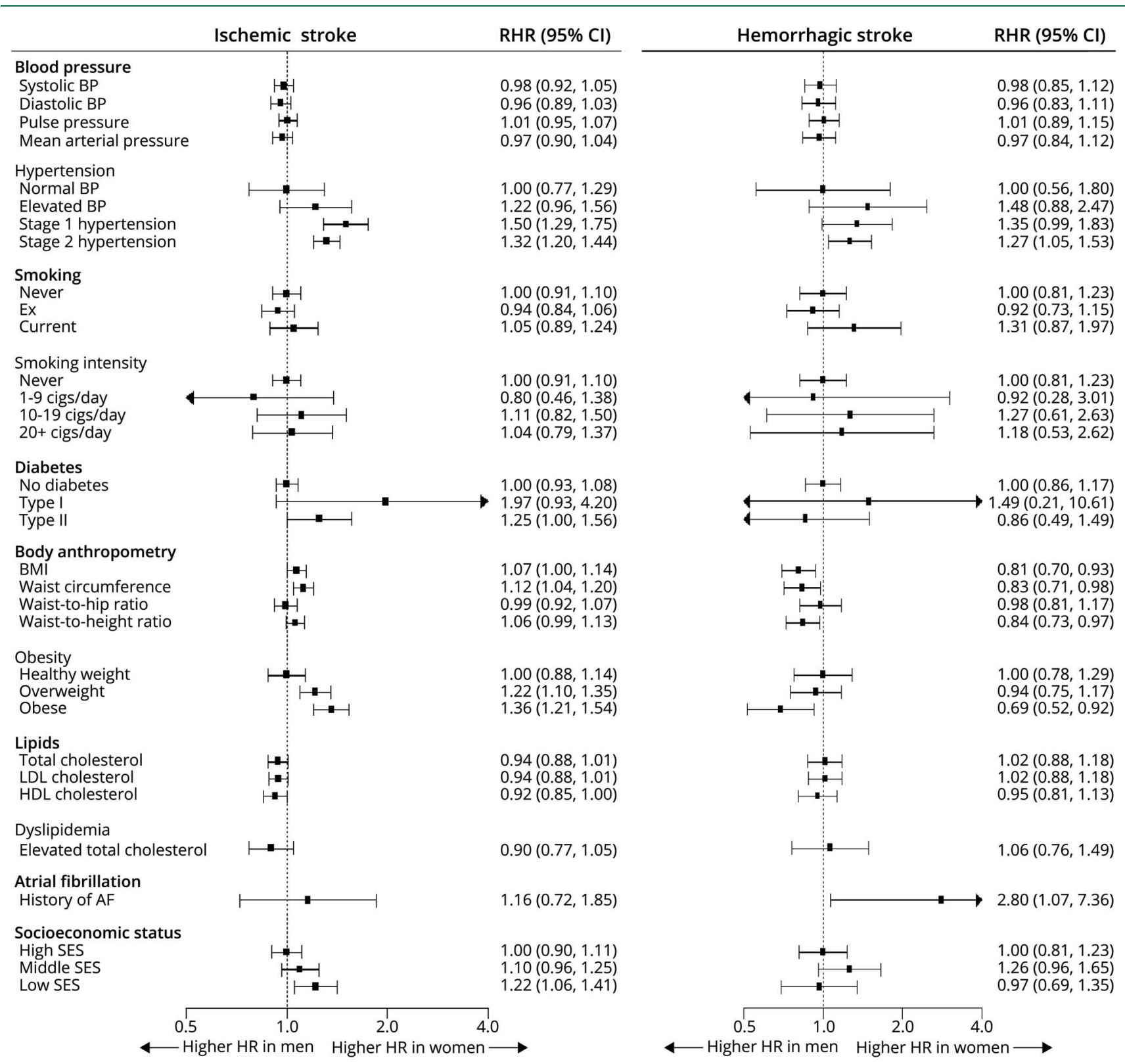

Horizontal lines indicate the corresponding 95\% confidence intervals (Cls) around the ratio of hazard ratios (RHRs). AF $=$ atrial fibrillation; $\mathrm{BMI}=$ body mass index; $\mathrm{BP}=$ blood pressure; $\mathrm{HDL}$ = high-density lipoprotein; $\mathrm{LDL}=$ low-density lipoprotein; $\mathrm{SES}=$ socioeconomic status.

\section{Lipids}

There was no evidence of a sex difference in the associations between different lipid fractions and any stroke or stroke subtypes. There was an inverse association between higher levels of total cholesterol and the risk of hemorrhagic stroke in both sexes (figure 2). A higher low-density lipoprotein was associated with a lower risk of hemorrhagic stroke in both sexes and with a higher risk of ischemic stroke in men only. There was an inverse association between higher levels of high-density lipoprotein cholesterol and the risk of any and ischemic stroke in both sexes (figure 1 and efigure 1, data available online at ora.ox.ac.uk/ objects/uuid:0866f6db-951d-4b3c-9bf9-40615161fa32).

\section{Atrial fibrillation}

A history of atrial fibrillation was associated with an increased risk of any stroke in both sexes; the HR was 3.27 (2.34-4.58) in women and $2.43(1.92-3.07)$ in men (efigure 1, data available online at ora.ox.ac.uk/objects/ uuid:0866f6db-951d-4b3c-9bf9-40615161fa32). The corresponding women-to-men ratio of HRs was 1.35 (0.90-2.02) (efigure 2). The risk of hemorrhagic stroke associated with atrial fibrillation was 4.38 (2.24-8.53) in women and $1.56(0.77-3.16)$ in men; the corresponding women-to-men ratio of HRs was 2.80 (1.07-7.36) (figures 2 and 3 ). 


\section{Socioeconomic status}

There was a graded relationship between socioeconomic status and the risk of any and ischemic stroke in both women and men. Compared to those with a higher socioeconomic status, the HRs of any stroke for those with a lower socioeconomic status were $1.45(1.32-1.59)$ in women and $1.24(1.14-1.35)$ in men, with a women-to-men ratio of HRs of 1.17 (1.03-1.33) (efigures 1 and 2, data available online at ora.ox.ac.uk/objects/uuid:0866f6db951d-4b3c-9bf9-40615161fa32). For ischemic stroke, the HRs were $1.55(1.38-1.73)$ for women and $1.27(1.15-1.39)$ for men, and the ratio of HRs was 1.22 (1.06-1.41) (figures 1 and 3).

\section{Sensitivity and subgroup analyses}

Results were broadly similar in the analyses adjusted for age only (etables 1-3, data available online at ora.ox.ac.uk/objects/ uuid:0866f6db-951d-4b3c-9bf9-40615161fa32). Subgroup analyses by age group demonstrated that the association between SBP and pulse pressure and any and ischemic stroke was stronger in men than women among those $<60$ years of age but not among those $\geq 60$ years of age (etables $4-6$ ). There was no evidence for interaction in the women-to-men ratios of HRs by socioeconomic status (etables 7-9). There was some evidence to suggest that the ratio of HRs for different stages of hypertension differed by the use of antihypertensive medication for any and ischemic stroke, with the sex differences being most profound among those using antihypertensive medication (etable 10). The ratios of HRs did not differ by glucose level-lowering medication (diabetes type 2 only), lipid levelregulating medication (lipid-related variables only), or use of warfarin (atrial fibrillation only) (etables 11-13).

\section{Sex comparisons of stroke rates}

The incidence rate of any stroke per 10,000 person-years was 8.66 (8.29-9.04) in women and 13.96 (13.44-14.50) in men. For ischemic stroke, the incidence rate was $6.06(5.75-6.38)$ in women and $11.35(10.88-11.84)$ in men. The incidence rate of hemorrhagic stroke was $1.56(1.41-1.73)$ in women and 2.23 $(2.02-2.45)$ in men. Atrial fibrillation was the only risk factor for which the unadjusted rate of stroke, particularly hemorrhagic stroke, was higher in women than men (etable 14-16, data available online at ora.ox.ac.uk/objects/uuid:0866f6db-951d4b3c-9bf9-40615161fa32). Type 1 diabetes was the only risk factor for which the multiple-adjusted rates of any stroke and both stroke subtypes was higher among women than men. For any stroke, the rates among those with type 1 diabetes were 37.77 per 10,000 person-years $(17.73-57.82)$ in women and 33.98 per 10,000 person-years $(15.98-51.97)$ in men (table 2 and etables 17 and 18). The higher rate among women than men with atrial fibrillation remained present for hemorrhagic stroke after adjustments: 7.69 per 10,000 person-years (2.57-12.81) in women and 2.90 per 10,000 person-years (0.86-4.93) in men.

\section{Discussion}

This study among 470,000 middle-aged women and men in the UK Biobank provides a comprehensive overview of the sex-specific association between major risk factors and the risk of stroke and stroke subtypes in later life. Stage 2 hypertension was associated with a $\approx 30 \%$ greater excess risk of both ischemic and hemorrhagic stroke in women than men. Obesity was associated with an $\approx 30 \%$ greater excess risk of ischemic stroke in women than men. Smoking conferred a $20 \%$ greater excess risk of any stroke in women than men. Type 2 diabetes was associated with a $25 \%$ greater excess risk of ischemic stroke in women than men. Women of lower socioeconomic status were $\approx 20 \%$ more likely to experience any stroke, mainly ischemic stroke. Atrial fibrillation was associated with an almost 3-fold greater excess risk of hemorrhagic stroke in women than men.

The present findings add to previous studies on the sex-specific association of major risk factors and the risk of stroke, including a series of systematic reviews with meta-analyses of the available literature. ${ }^{5-10}$ Pooled analyses of 1 million individuals and $>20,000$ strokes demonstrated that every $10-\mathrm{mm} \mathrm{Hg}$ increment in SBP was associated with an increased risk of stroke of $\approx 25 \%$ in both women and men. ${ }^{9}$ A more recent study of 1.25 million individuals in the United Kingdom demonstrated that the association between SBP and DBP and the risk of several stroke subtypes was similar between the sexes. ${ }^{15}$ The current study shows that these findings can be expanded to pulse pressure and mean arterial pressure and suggests that SBP and mean arterial pressure have the strongest association with the risk of stroke in both sexes. In addition, this study demonstrates that women with hypertension have a greater excess risk of first stroke than their male counterparts, which is consistent with the INTERSTROKE study. ${ }^{2}$ The sex difference was most profound among those using antihypertensive medication, suggesting that women face a greater residual risk of stroke than men once treatment has been initiated. The Reasons for Geographic and Racial Differences in Stroke (REGARDS) study among $>26,000$ participants also demonstrated that the association between the severity of hypertension and ischemic stroke was stronger in women than men; the HRs were 1.25 in women (95\% CI, 1.16-1.34) vs 1.14 (1.05-1.23) in men. ${ }^{16}$ The mechanisms underpinning the potential sex-specific effects of hypertension on the risk of stroke warrant further research but, if confirmed, may be biological or related to sex differences in the management of blood pressure. Recent data from the United States and China showed that the control of hypertension should be improved in both sexes but is better in women than men. ${ }^{17,18}$ Clinical trials show no evidence of sex differences in the effectiveness of blood pressure-lowering medication on cardiovascular events. ${ }^{19,20}$ Yet, women remain underrepresented in stroke trials, so studies have not been designed to conclusively assess sex-specific effects, or side effects, of blood pressure treatments. ${ }^{21}$ Additional research is required to elucidate why there is evidence for a sex difference in the relationship between hypertension and the risk of stroke, whereas the association between SBP and other blood pressure indices and stroke risk is similar between the sexes. Previous analyses in the UK Biobank cohort showed a similar discrepancy, indicating that the explanations may not be specific to stroke. $^{22}$ 
Table 2 Multiple-adjusted rates of stroke (per 10,000 person-years) by sex and women-to-men difference of rate differences for each risk factor

\begin{tabular}{|c|c|c|c|}
\hline & Women & Men & Difference of rate differences \\
\hline \multicolumn{4}{|l|}{ Hypertension } \\
\hline Normal BP & $6.01(5.09-6.92)$ & $11.64(9.65-13.63)$ & \\
\hline Elevated BP & $7.19(6.13-8.24)$ & $10.54(8.99-12.09)$ & $-2.28(-5.12$ to 0.57$)$ \\
\hline Stage 1 hypertension & $8.60(7.79-9.41)$ & $10.68(9.70-11.65)$ & $-3.56(-6.06$ to -1.05$)$ \\
\hline Stage 2 hypertension & $10.51(9.84-11.18)$ & $15.11(14.35-15.88)$ & $-1.03(-3.46$ to 1.40$)$ \\
\hline \multicolumn{4}{|l|}{ Smoking status } \\
\hline Never & $8.01(7.53-8.49)$ & $12.20(11.45-12.94)$ & \\
\hline Ex & $8.06(7.43-8.68)$ & $13.34(12.53-14.15)$ & $1.10(-0.26$ to 2.46$)$ \\
\hline Current & $17.00(15.08-18.92)$ & $22.28(20.23-24.33)$ & $1.09(-1.85$ to 4.04$)$ \\
\hline \multicolumn{4}{|l|}{ Smoking intensity } \\
\hline Never & $7.47(7.02-7.92)$ & $11.47(10.78-12.17)$ & \\
\hline 1-9 cigarettes/d & $12.35(8.70-16.01)$ & $17.04(11.38-22.69)$ & $0.68(-6.11$ to 7.47$)$ \\
\hline 10-19 cigarettes/d & $17.26(14.11-20.40)$ & $21.51(17.51-25.52)$ & $0.25(-4.92$ to 5.42$)$ \\
\hline$\geq 20$ cigarettes $/ d$ & $22.16(17.72-26.59)$ & $31.29(26.62-35.97)$ & $5.13(-1.38$ to 11.64$)$ \\
\hline \multicolumn{4}{|l|}{ Diabetes } \\
\hline No diabetes & $8.84(8.39-9.28)$ & $12.49(11.94-13.04)$ & \\
\hline Type 1 & $37.77(17.73-57.82)$ & $33.98(15.98-51.97)$ & $-7.45(-34.41$ to 19.50$)$ \\
\hline Type 2 & $13.22(10.75-15.68)$ & $19.60(16.89-22.32)$ & $2.73(-1.01$ to 6.48$)$ \\
\hline \multicolumn{4}{|l|}{ BMI categories } \\
\hline Healthy weight & $7.97(7.36-8.57)$ & $12.94(11.93-13.96)$ & \\
\hline Overweight & $8.60(7.99-9.22)$ & $12.78(12.05-13.50)$ & $-0.80(-2.31$ to 0.72$)$ \\
\hline Obese & $10.61(9.74-11.49)$ & $15.73(14.57-16.89)$ & $0.14(-1.73$ to 2.02$)$ \\
\hline \multicolumn{4}{|l|}{ Cholesterol } \\
\hline Normal TC & $9.34(8.78-9.90)$ & $13.14(12.51-13.76)$ & \\
\hline High TC & $9.02(8.39-9.65)$ & $12.70(11.77-13.64)$ & $-0.11(-1.53$ to 1.31$)$ \\
\hline \multicolumn{4}{|l|}{ Atrial fibrillation } \\
\hline No AF & $9.08(8.64-9.51)$ & $12.73(12.18-13.27)$ & \\
\hline History of AF & $28.76(19.10-38.42)$ & $31.36(24.08-38.64)$ & $-1.05(-13.16$ to 11.06$)$ \\
\hline \multicolumn{4}{|l|}{ Socioeconomic status } \\
\hline High SES & $8.07(7.50-8.64)$ & $12.16(11.46-12.87)$ & \\
\hline Middle SES & $9.74(8.94-10.54)$ & $12.90(11.91-13.88)$ & $-0.93(-2.47$ to 0.60$)$ \\
\hline Low SES & $11.44(10.34-12.54)$ & $15.27(13.92-16.62)$ & $-0.26(-2.21$ to 1.69$)$ \\
\hline
\end{tabular}

Abbreviations: $\mathrm{AF}=$ atrial fibrillation; $\mathrm{BMI}=$ body mass index; $\mathrm{BP}=$ blood pressure; $\mathrm{SES}=$ socioeconomic status; $\mathrm{TC}=$ total cholesterol.

A meta-analysis involving nearly 4 million individuals and $>42,000$ strokes found that the excess risk of stroke was at least as great among women who smoke compared with men who smoke. ${ }^{8}$ Although there was no overall evidence of a sex difference in smoking-related risk of stroke, there was a significant $10 \%$ greater excess risk of stroke among women who smoke compared to men who smoke in Western populations, in which the smoking epidemic among women is more mature than in non-Western populations. Hence, the potential sex difference in the effect of smoking on the risk of 
stroke might not have been visible in older studies due to substantial sex differences in smoking behavior and the relative immaturity of the smoking epidemic in women in most parts of the world. ${ }^{23}$ In previous analyses in the UK Biobank, we demonstrated that differences in smoking behavior between women and men have decreased over time. ${ }^{24}$ This analysis showed that the excess risk of stroke may indeed be greater in women who smoke compared with men who smoke in populations in which the full hazards of smoking are discernible in both sexes. However, the observation that the sex difference seemed to decrease with an increasing number of cigarettes smoked suggests that other mechanisms than the harmful effects of tobacco alone might underpin women's excess risk.

Diabetes is a strong risk factor for stroke, with evidence from previous meta-analyses to suggest that the excess risk of stroke associated with diabetes is $27 \%$ greater in women than men, independently of other stroke risk factors. ${ }^{7}$ Because $90 \%$ of individuals with diabetes have type 2 diabetes, most individuals with diabetes who were included in these meta-analyses had type 2 diabetes. Nevertheless, a meta-analysis that focused specifically on type 1 diabetes has shown that women with type 1 diabetes had an almost $37 \%$ higher relative risk of all-cause stroke compared with men with type 1 diabetes. ${ }^{10}$ Subsequent studies have reported mixed findings on the presence of sex difference in the risk of stroke associated with diabetes. ${ }^{25-27} \mathrm{~A}$ study among 150,000 Mexican adults demonstrated that the risk of all-cause mortality associated with diabetes was similar between the sexes, and although not reported, the authors also indicated that there were no sex differences in the risk of cerebrovascular disease associated with diabetes. ${ }^{25}$ Similarly, a UK study including nearly 2 million individuals found no evidence to suggest that the association between diabetes and stroke subtypes differed between women and men. ${ }^{26}$ The China Kadoorie Biobank study of 500,000 individuals provided some support for sex differences in the diabetes-associated risk of vascular diseases, but the difference for stroke did not reach statistical significance. ${ }^{27}$ Moreover, the sex differences were seen mainly in individuals with previously diagnosed diabetes rather than among those whose diabetes was first detected at study baseline. Albeit not statistically significant, the current study provides some evidence to suggest that the sex differences in the excess risk of stroke associated with diabetes were seen primarily among those without antidiabetic medications, indicating that sex differences in the treatment of diabetes may be an important contributor to the sex-specific effects. Taken together, the present and past findings heighten the need for further studies into the sex-specific effects of diabetes on the risk of stroke, because any sex differences can have meaningful implications for the prevention of stroke and other major diabetes complications.

In agreement with previous analyses, we found that overweight and obesity increased the risk of any stroke to a similar extent in women and men. ${ }^{28}$ However, a higher risk of ischemic stroke was associated with obesity in women. Unlike
INTERSTROKE, we did not find evidence of a sex difference in the association between waist-to-hip ratio or other indices of body anthropometry and the risk of stroke. ${ }^{2}$ A lower socioeconomic status is related to a higher risk of stroke in the present study with the magnitude of the excess risk higher in women than men. This finding does not concur with the results from a meta-analysis that reported that a lower socioeconomic status increased the risk of coronary heart disease and all cardiovascular disease, but not stroke, to a significantly greater extent in women than men. ${ }^{5}$ Consistent with previous studies, we found no sex difference in the effects of raised cholesterol and the risk of stroke. In addition, while the effect of elevated cholesterol on stroke risk was small and varied across stroke subtypes, additional analyses showed that raised total cholesterol and low-density lipoprotein cholesterol were strongly associated with a higher risk of myocardial infarction (MI) (etable 19, data available online at ora.ox.ac. uk/objects/uuid:0866f6db-951d-4b3c-9bf9-40615161fa32).

A pooled analysis of 11 studies with 83,000 stroke events demonstrated that the excess risk of stroke associated with a history of atrial fibrillation was twice as large in women as in men. ${ }^{6}$ In the present study, we also found that atrial fibrillation was associated with a considerably greater excess risk of stroke in women than men, mainly hemorrhagic stroke. Several factors may contribute to women's greater excess risk of stroke in the presence of atrial fibrillation. First, women with atrial fibrillation may be undertreated relative to men. In 2001, a Canadian study found that the use of anticoagulants among patients with newly diagnosed atrial fibrillation was lower in women than men, despite comparable risk profiles. ${ }^{29}$ A more recent UK report also demonstrated relative underuse of anticoagulant therapy in women, which decreased as initiation of anticoagulant therapy rose from $48 \%$ in men and $40 \%$ in women in 2000 to $58 \%$ in men and $52 \%$ in women in $2012 .^{30}$ Alternatively, physiologic differences might also explain the sex-specific effects of atrial fibrillation on the risk of stroke. For example, the response to oral anticoagulants might differ between women and men, with a $20 \%$ higher risk of bleeding observed among women. ${ }^{31}$ This increased bleeding risk may explain the higher risk for hemorrhagic stroke in women. Furthermore, the Biomarker for Cardiovascular Risk Assessment in Europe (BiomarCaRE) Consortium reported that excess BMI and lower total cholesterol were more strongly associated with the risk of atrial fibrillation in men than women. ${ }^{32}$ In the present study, adjustment for these risk factors attenuated, but did not completely remove, women's excess risk. Further studies are needed to further elucidate the potentially sex-specific pathophysiology of atrial fibrillation and its relevance to clinical practice.

The clinical implications of sex differences in the association risk factors and the risk of stroke depend on their effect on the overall risk of stroke. In previous analyses of the UK Biobank cohort, we showed that several risk factors were more strongly associated with the risk of $\mathrm{MI}$ in women than men. ${ }^{22}$ However, we also showed that these greater relative risks among women did not result in a higher overall risk of MI. In this 
study, we found that type 1 diabetes and, for hemorrhagic stroke, atrial fibrillation were the only risk factors for which the rates of stroke were higher among women than men. Given the relatively low prevalence of these conditions, any excess relative risk among women is unlikely to have a major effect on the overall rate of stroke. For all other risk factors, women were at a lower overall risk of stroke, despite a stronger relative effect of some risk factors on the onset of stroke. Women and men may require additional support and individualized care to control risk factors in stroke.

The strengths of this study include its prospective design, the large sample size, and the extensive phenotypic detail available on all participants. Compared with previous meta-analyses, the present study benefited from the availability of participant-level data on multiple risk factors and stroke subtypes, thereby allowing more detailed, standardized, and flexible examination of the sex-specific association between major risk factors and the risk of any, ischemic, and hemorrhagic stroke. Some limitations also need to be mentioned. First, the UK Biobank is a relatively healthy population, and the number of events for stroke subtypes was too limited to produce reliable sex-specific estimates. Information on smoking status, diabetes, atrial fibrillation, and medication use was self-reported, which will have introduced measurement error that could conceivably be differential by sex. In addition, although we adjusted our analyses for several a priori-selected confounders, we also cannot exclude the possibility of residual confounding, as in any observational study. Finally, >90\% of participants had a White ancestry, so the results may not be generalizable to other ethnicities.

Several risk factors are more strongly associated with the risk of any stroke or stroke subtypes in women compared with men. Despite this, the incidence of stroke in the presence of risk factors generally remains higher among men than women.

\section{Acknowledgment}

This research has been conducted using the UK Biobank Resource (application No. 2495). This work is dedicated to the memory Dr. Elizabeth Millett, our friend and colleague, who passed away before the submission of this paper.

\section{Study funding}

S.A.E. Peters is supported by a UK Medical Research Council Skills Development Fellowship (MR/P014550/1). M. Woodward is supported by the National Health and Medical Research Foundation of Australia (1080206).

\section{Disclosure}

S.A.E. Peters, C. Carcel, and E. Millett have no relevant disclosures. M. Woodward has received consulting fees from Amgen, Inc and Kyowa Kirin Co., Ltd. Go to Neurology.org/ $\mathrm{N}$ for full disclosures.

\section{Publication history}

Received by Neurology October 30, 2019. Accepted in final form May 11, 2020.

\section{Appendix Authors}

\begin{tabular}{lll}
\hline Name & Location & Contribution \\
\hline $\begin{array}{l}\text { Sanne A.E. } \\
\text { Peters, PhD }\end{array}$ & $\begin{array}{l}\text { The George Institute for } \\
\text { Global Health, University } \\
\text { of Oxford, UK }\end{array}$ & $\begin{array}{l}\text { Design and conceptualized } \\
\text { study; analyzed the data; } \\
\text { interpreted the data; } \\
\text { drafted the manuscript for } \\
\text { intellectual content }\end{array}$ \\
$\begin{array}{l}\text { Cheryl } \\
\begin{array}{l}\text { Carcel, MD, } \\
\text { PhD }\end{array}\end{array}$ & $\begin{array}{l}\text { The George Institute for } \\
\text { of New South Wales, }\end{array}$ & $\begin{array}{l}\text { Interpreted the data; } \\
\text { revised the manuscript for } \\
\text { intellectual content }\end{array}$ \\
$\begin{array}{l}\text { Elizabeth } \\
\text { R.C. Millett, } \\
\text { PhD }\end{array}$ & $\begin{array}{l}\text { The George Institute for } \\
\text { Global Health, University } \\
\text { of Oxford, UK }\end{array}$ & $\begin{array}{l}\text { Analyzed the data; } \\
\text { interpreted the data; } \\
\text { revised the manuscript for } \\
\text { intellectual content }\end{array}$ \\
$\begin{array}{l}\text { Mark } \\
\text { Woodward, } \\
\text { PhD }\end{array}$ & $\begin{array}{l}\text { The George Institute for } \\
\text { Global Health, University } \\
\text { of Oxford, UK }\end{array}$ & $\begin{array}{l}\text { Design and conceptualized } \\
\text { study; interpreted the data; } \\
\text { revised the manuscript for } \\
\text { intellectual content }\end{array}$ \\
\hline
\end{tabular}

\section{References}

1. Institute for Health Metrics and Evaluation. GBD compare data visualization. 2017. Available at: vizhub.healthdata.org/gbd-compare.

2. O'Donnell MJ, Chin SL, Rangarajan S, et al. Global and regional effects of potentially modifiable risk factors associated with acute stroke in 32 countries (INTERSTROKE): a case-control study. Lancet 2016;388:761-775.

3. Barker-Collo S, Bennett DA, Krishnamurthi RV, et al. Sex differences in stroke incidence, prevalence, mortality and disability-adjusted life years: results from the Global Burden of Disease Study 2013. Neuroepidemiology 2015;45:203-214.

4. Reeves MJ, Bushnell CD, Howard G, et al. Sex differences in stroke: epidemiology, clinical presentation, medical care, and outcomes. Lancet Neurol 2008;7:915-926.

5. Backholer K, Peters SAE, Bots SH, Peeters A, Huxley RR, Woodward M. Sex differences in the relationship between socioeconomic status and cardiovascular disease: a systematic review and meta-analysis. J Epidemiol Community Health 2017;71:550-557.

6. Emdin CA, Wong CX, Hsiao AJ, et al. Atrial fibrillation as risk factor for cardiovascular disease and death in women compared with men: systematic review and meta-analysis of cohort studies. BMJ 2016;532:h7013.

7. Peters SA, Huxley RR, Woodward M. Diabetes as a risk factor for stroke in women compared with men: a systematic review and meta-analysis of 64 cohorts, including 775,385 individuals and 12,539 strokes. Lancet 2014;383:1973-1980.

8. Peters SA, Huxley RR, Woodward M. Smoking as a risk factor for stroke in women compared with men: a systematic review and meta-analysis of 81 cohorts, including 3,980,359 individuals and 42,401 strokes. Stroke 2013;44:2821-2828.

9. Peters SA, Huxley RR, Woodward M. Comparison of the sex-specific associations between systolic blood pressure and the risk of cardiovascular disease: a systematic review and meta-analysis of 124 cohort studies, including 1.2 million individuals. Stroke 2013;44:2394-2401.

10. Huxley RR, Peters SA, Mishra GD, Woodward M. Risk of all-cause mortality and vascular events in women versus men with type 1 diabetes: a systematic review and meta-analysis. Lancet Diabetes Endocrinol 2015;3:198-206.

11. Allen N, Sudlowa C, Downey P, et al. UK Biobank: current status and what it means for epidemiology. Health Pol Technol 2012;1:123-126.

12. Sudlow C, Gallacher J, Allen N, et al. UK Biobank: an open access resource for identifying the causes of a wide range of complex diseases of middle and old age. PLoS Med 2015;12:e1001779.

13. Whelton PK, Carey RM, Aronow WS, et al. 2017 ACC/AHA/AAPA/ABC/ACPM/ AGS/APhA/ASH/ASPC/NMA/PCNA guideline for the prevention, detection, evaluation, and management of high blood pressure in adults: a report of the American College of Cardiology/American Heart Association Task Force on Clinical Practice Guidelines. J Am Coll Cardiol 2018;71:1269-1324.

14. Woodward M. Rationale and tutorial for analysing and reporting sex differences in cardiovascular associations. Heart 2019;105:1701-1708.

15. Rapsomaniki E, Timmis A, George J, et al. Blood pressure and incidence of twelve cardiovascular diseases: lifetime risks, healthy life-years lost, and age-specific associations in 1.25 million people. Lancet 2014;383:1899-1911.

16. Madsen TE, Howard G, Kleindorfer DO, et al. Sex differences in hypertension and stroke risk in the REGARDS study: a longitudinal cohort study. Hypertension 2019; 74:749-755.

17. Peters SAE, Muntner P, Woodward M. Sex differences in the prevalence of, and trends in, cardiovascular risk factors, treatment, and control in the United States, 2001 to 2016. Circulation 2019;139:1025-1035.

18. Redfern A, Peters SAE, Luo R, et al. Sex differences in the awareness, treatment, and control of hypertension in China: a systematic review with meta-analyses. Hypertens Res 2019;42:273-283. 
19. Foy CG, Lovato LC, Vitolins MZ, et al. Gender, blood pressure, and cardiovascular and renal outcomes in adults with hypertension from the Systolic Blood Pressure Intervention Trial. J Hypertens 2018;36:904-915.

20. Turnbull F, Woodward M, Neal B, et al. Do men and women respond differently to blood pressure-lowering treatment? Results of prospectively designed overviews of randomized trials. Eur Heart J 2008;29:2669-2680.

21. Carcel C, Woodward M, Balicki G, et al. Trends in recruitment of women and reporting of sex differences in large-scale published randomized controlled trials in stroke. Int J stroke 2019;14:931-938.

22. Millett ERC, Peters SAE, Woodward M. Sex differences in risk factors for myocardial infarction: cohort study of UK Biobank participants. BMJ 2018;363: $\mathrm{k} 4247$.

23. Peters SA, Van der Schouw YT, Woodward M, Huxley RR. Sex differences in smoking-related risk of vascular disease and all-cause mortality. Curr Cardiovasc Risk Rep 2013;7:473-479.

24. Peters SA, Huxley RR, Woodward M. Do smoking habits differ between women and men in contemporary Western populations? Evidence from half a million people in the UK Biobank Study. BMJ Open 2014;4:e005663.

25. Alegre-Diaz J, Herrington W, Lopez-Cervantes M, et al. Diabetes and cause-specific mortality in Mexico City. N Engl J Med 2016;375:1961-1971.
26. Dinesh Shah A, Langenberg C, Rapsomaniki E, et al. Type 2 diabetes and incidence of a wide range of cardiovascular diseases: a cohort study in 1.9 million people. Lancet 2015;385( suppl 1):S86.

27. Bragg F, Holmes MV, Iona A, et al. Association between diabetes and cause-specific mortality in rural and urban areas of China. JAMA 2017;317:280-289.

28. Global BMI Mortality Collaboration, Di Angelantonio E, Bhupathiraju ShN, Wormser $\mathrm{D}$, et al. Body-mass index and all-cause mortality: individual-participant-data metaanalysis of 239 prospective studies in four continents. Lancet 2016;388:776-786.

29. Humphries KH, Kerr CR, Connolly SJ, et al. New-onset atrial fibrillation: sex differences in presentation, treatment, and outcome. Circulation 2001;103:2365-2370.

30. Scowcroft AC, Cowie MR. Atrial fibrillation: improvement in identification and stroke preventive therapy - data from the UK Clinical Practice Research Datalink, 20002012. Int J Cardiol 2014;171:169-173.

31. Alotaibi GS, Almodaimegh H, McMurtry MS, Wu C. Do women bleed more than men when prescribed novel oral anticoagulants for venous thromboembolism? A sexbased meta-analysis. Thromb Res 2013;132:185-189.

32. Magnussen C, Niiranen TJ, Ojeda FM, et al. Sex differences and similarities in atrial fibrillation epidemiology, risk factors, and mortality in community cohorts: results from the BiomarCaRE Consortium (Biomarker for Cardiovascular Risk Assessment in Europe). Circulation 2017;136:1588-1597. 


\section{Neurology}

\section{Sex differences in the association between major risk factors and the risk of stroke in the UK Biobank cohort study \\ Sanne A.E. Peters, Cheryl Carcel, Elizabeth R.C. Millett, et al.}

Neurology 2020;95;e2715-e2726 Published Online before print October 16, 2020

DOI 10.1212/WNL.0000000000010982

This information is current as of October 16, 2020

\section{Updated Information \&} Services

\section{References}

Citations

Subspecialty Collections

\section{Permissions \& Licensing}

Reprints including high resolution figures, can be found at: http://n.neurology.org/content/95/20/e2715.full

This article cites 31 articles, 8 of which you can access for free at: http://n.neurology.org/content/95/20/e2715.full\#ref-list-1

This article has been cited by 2 HighWire-hosted articles: http://n.neurology.org/content/95/20/e2715.full\#\#otherarticles

This article, along with others on similar topics, appears in the following collection(s):

\section{All Cerebrovascular disease/Stroke}

http://n.neurology.org/cgi/collection/all_cerebrovascular_disease_strok e

\section{Cohort studies}

http://n.neurology.org/cgi/collection/cohort_studies

\section{Gender}

http://n.neurology.org/cgi/collection/gender

Risk factors in epidemiology

http://n.neurology.org/cgi/collection/risk_factors_in_epidemiology

Information about reproducing this article in parts (figures,tables) or in its entirety can be found online at:

http://www.neurology.org/about/about_the_journal\#permissions

Information about ordering reprints can be found online:

http://n.neurology.org/subscribers/advertise

Neurology ${ }^{\circledR}$ is the official journal of the American Academy of Neurology. Published continuously since 1951, it is now a weekly with 48 issues per year. Copyright Copyright ( 2020 The Author(s). Published by Wolters Kluwer Health, Inc. on behalf of the American Academy of Neurology.. All rights reserved. Print ISSN: 0028-3878. Online ISSN: 1526-632X.

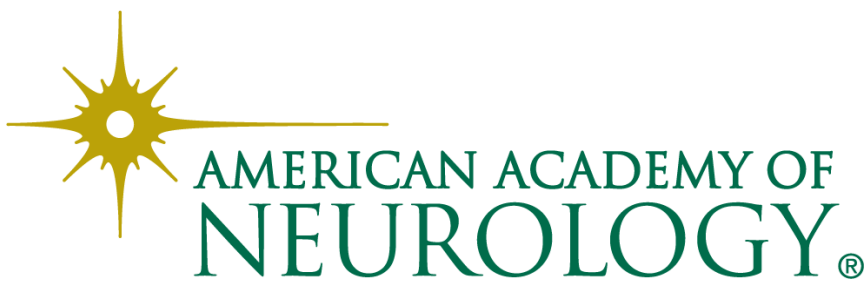

